\title{
Contando histórias: categorização de pertencimento e instruções-em-ação em um ambiente de ensino e aprendizagem de PLA
}

\section{Telling stories: Membership Categorization and Instructions-in-Action in a teaching- learning environment of Portuguese as an Additional Language (PAL)}

\author{
Bruna Morelo* \\ *University of Macau, Taipa, Macau / China \\ brunamorelo@hotmail.com \\ https://orcid.org/0000-0003-4142-5729 \\ Ricardo Moutinho** \\ **University of Macau, Taipa, Macau / China \\ moutinho@um.edu.mo \\ http://orcid.org/0000-0002-9625-1116
}

\begin{abstract}
RESUMO: Neste estudo, analisamos interações entre participantes de um curso de contação de histórias em Português como Língua Adicional (PLA), ofertado como disciplina opcional em uma universidade do interior da China. Levando em consideração que para se entender as atividades da vida diária, é necessário olharmos para como as pessoas agem e fazem sentido dessas ações localmente, esta pesquisa adota o aporte metodológico da Etnometodologia e da Análise da Conversa. Por meio da observação dos dados gerados através de gravação audiovisual de uma das aulas do curso em questão, constatamos um trabalho categorizacional (i.e.: a produção de tipos particulares de itens sequenciais informada pela orientação dos interagentes a categorias de pertencimento presentes na sociedade; p.e.: professor, aluno, médico, paciente etc.) por parte dos participantes do curso, que, unido ao sentido que esses participantes fazem (na interação) das instruções sobre como participar das aulas, revela a complexa relação reflexiva entre planejamento pedagógico e interação em sala de aula de língua adicional.
\end{abstract}

PALAVRAS-CHAVE: contação de histórias; etnometodologia e análise da conversa; português língua adicional; análise de categorização de pertencimento; instruções-em-ação. 


\begin{abstract}
This study analyses interactions among participants in a storytelling course of PAL, offered as an elective course in a university located in Mainland China. Based on the idea that, in order to understand daily-life activities, we need to look at how people act and make sense of their actions locally, this study takes on an Ethnomethodological and Conversation Analytic approach. The results generated through audiovisual recordings from one of the meetings of the abovementioned course show a constant categorial work (i.e.: the production of particular types of sequential items informed by an orientation to the membership categories present in the society; e.g.: 'teacher', 'student', 'doctor', 'patient' etc.) of members in the course, which, along with the sense that these members make (in situ) of the instructions on how to participate in the lessons, reveal the complex reflexive relationship between pedagogy and interaction in an AL classroom.
\end{abstract}

KEYWORDS: storytelling; ethnomethodology and conversation analysis; Portuguese as an additional language; membership categorization analysis; instructions-in-action.

\title{
1 Introdução
}

O presente trabalho descreve e analisa interações entre participantes de um curso de contação de histórias no contexto de ensino e aprendizagem de Português Língua Adicional (PLA). O objetivo do estudo é contribuir para o entendimento de abordagens centradas na oralidade e na interação que ocorrem em salas de aula onde os turnos de fala têm por base uma sistemática pouco pré-alocada, ou seja, mais próxima ao que ocorre em conversas cotidianas (SACKS; SCHEGLOFF; JEFFERSON, 1974), havendo mais possibilidades de formas de participação e de mobilização de categorias sociais diferentes das comumente encontradas em sala de aula.

A aproximação à conversa cotidiana é desejável, uma vez que, para se aprender uma língua adicional, uma produção oral menos ritualizada favorece, por exemplo, o desenvolvimento de uma competência interacional para a tomada e/ou manutenção do turno de fala. Tal competência é mais difícil de ser desenvolvida em um ambiente em que os turnos são alocados apenas pelo professor, visto que dá ao aprendiz poucas oportunidades de "tomar a palavra" e expor as suas ideias e opiniões na língua-alvo.

A partir da concepção de que, para compreender as atividades da vida cotidiana (incluindo aquelas realizadas em ambientes educacionais) é preciso olhar para como as pessoas agem e fazem sentido dessas ações localmente, este trabalho adota o aporte metodológico da Etnometodologia (EM) e da Análise da Conversa Etnometodológica (ACE). Ambas as disciplinas têm 
como principal interesse os métodos usados pelas pessoas comuns para dar sentido às coisas do mundo.

A observação e a descrição de atividades do curso de contação de histórias contribuem também para as discussões sobre a relação reflexiva entre a pedagogia utilizada e as interações em sala de aula de língua adicional, que abordam como a organização da interação varia de acordo com o foco pedagógico (SEEDHOUSE, 2004, 2015). O curso conta com um planejamento baseado na pedagogia de projetos (GREENO, 2006; MARKHAM, 2011), metodologia de ensino e aprendizagem que propõe um envolvimento ativo dos participantes em diversas etapas e atividades que culminam em um produto final que, no curso em questão, refere-se a uma contação de histórias para um público-alvo específico.

Em projetos, a elaboração e a organização das atividades pedagógicas são orientadas para a construção desse produto concreto. Essa proposta prevê práticas de sala de aula que respeitem os conhecimentos trazidos pelos educandos, valorizem a diversidade, o diálogo e a construção compartilhada de conhecimentos significativos para uma participação mais autoral (SCHLATTER; GARCEZ, 2012).

A pedagogia de projetos caracteriza-se por proporcionar ensino e aprendizagem "em situações concretas, de interação, como um processo contínuo e dinâmico" (BARBOSA, 2004, p. 11) e em "vivências significativas com o conhecimento" (SCHLATTER; GARCEZ, 2012, p. 14). Nesse sentido a sala de aula não é um lugar para simulações ou para "fazer de conta", a possibilidade de publicização do produto pode ressignificar a motivação e a participação nas atividades.

$\mathrm{Na}$ perspectiva etnometodológica, a sala de aula, as atividades de ensinar e aprender fazem parte do que é mundano e rotineiro. Conforme apontado por Payne e Cuff (1982), muitos aspectos do "fazer sala de aula" parecem carregar um toque de trivialidade, pela maneira natural e corriqueira que os afazeres são conduzidos. Assim, a maioria dessas atividades é tomada como garantida, pois elas são interpretadas como óbvias, contudo, há muito mais envolvido.

Ainda de acordo com Payne e Cuff (1982, p. 3), "o estudo da realização do que é mundano muitas vezes pode iluminar aspectos de preocupações educacionais mais amplas de maneiras inesperadas". ${ }^{1}$ Uma sala de aula - e

\footnotetext{
${ }^{1}[\ldots]$ study of the accomplishment of the mundane can often illuminate aspects of wider educational concerns in unexpected ways.
} 
o estudo sobre ela - em que o ensino e a aprendizagem são realizados por projetos pode, então, ser um cenário para ampliarmos nossos entendimentos dos fazeres educacionais. Nesse sentido, esta pesquisa investiga etnométodos - fenômenos - que se tornaram salientes em uma sala de aula de PLA em que o ensino e a aprendizagem da oralidade se dão através de um projeto.

Partimos do pressuposto que é na interação que o projeto toma corpo e faz sentido, pois é por meio da complexa ação dos participantes que as instruções das atividades são concretizadas para todos os propósitos práticos. Com base nisso, neste estudo, examinamos como o planejamento das atividades é atualizado no "aqui e agora" das interações de um curso de contação de histórias, um gênero discursivo ainda pouco discutido e explorado nos trabalhos sobre fala-em-interação em sala de aula de língua adicional e nos programas de ensino de línguas pelo Brasil.

Além disso, examinamos o trabalho de categorização de pertencimento realizado pelos participantes desse curso, ou seja, como as ações dos participantes produzem categorias de pertencimento para além daquelas mais corriqueiras em sala de aula de línguas (como professor/aluno). Assim, mostraremos como um curso de contação pode alavancar diferentes tipos de participação, uma vez que quem conta a história não é necessariamente a professora, fato esse que democratiza a responsabilidade e o direito de compartilhar o saber, já que todos devem estar ativamente cooperando para que a atividade seja realizada.

Este artigo está organizado em cinco partes. Na próxima seção, apresentaremos os fenômenos de categorização de pertencimento e de instruções-em-ação. Em seguida, explicaremos a nossa orientação metodológica e o contexto de geração de dados. Na parte seguinte, com base na orientação categorizacional assumida pelos participantes do curso de contação, faremos uma discussão acerca dados coletados, o que será feito em duas partes: uma destinada a como os participantes fazem sentido das instruções do curso e outra à produção colaborativa de enunciados. $\mathrm{Na}$ última parte, teceremos algumas considerações finais.

\section{Categorização de pertencimento e instruções-em-ação}

Nesta seção, faremos uma breve apresentação dos fenômenos que estão mais salientes em nossos dados (categorização de pertencimento e instruções-em-ação), os quais serão analisados mais à frente na parte destinada à discussão dos dados gerados em sala de aula. 


\subsection{Categorização de pertencimento}

Um ponto que nos parece fundamental ao estudo aqui apresentado é a produção e o gerenciamento de categorias de pertencimento, tópico muito abordado nos estudos de Análise de Categorização de Pertencimento $(\mathrm{MCA})^{2}$ e que se refere às práticas pelas quais são associadas características e atividades, produzidas no momento da interação, a certas categorias particulares presentes na sociedade (p.e.: professor, aluno, médico, paciente). Por esse mecanismo é realizado um trabalho interacional de relacionar alguém como membro pertencente a alguma categoria específica (SACKS, 1972, 1995; SPEIER, 1970).

É importante mencionar, no entanto, que a produção de categorias de pertencimento não se assemelha ao conceito de papéis, por este se tratar de um conceito fixo, com características baseadas em definições apriorísticas e que muitas vezes não condiz com o posicionamento que os participantes assumem ao longo das interações. Em vez disso, a EM reespecifica o conceito de papéis (ou "identidades") por meio do fenômeno de categorização de pertencimento. As categorizações são recursos aos quais os participantes de uma interação orientam-se para fazer sentido das pessoas e das suas ações no mundo. Esses recursos, por serem dinâmicos, podem tornar-se mais ou menos relevantes a depender das organizações endógenas das interações.

Em seus estudos, Harvey Sacks $(1972,1995)$ desenvolveu uma série de apontamentos e considerações relacionados ao trabalho de categorização, um aparato que informa como podemos entender localmente, na interação, certas escolhas categoriais em detrimento de outras. Essas escolhas estão relacionadas aos dispositivos de categorização, que podem fazer com que uma categoria específica seja mobilizada (o dispositivo "estágio de vida", por exemplo, pode mobilizar as categorias criança, adolescente, adulto, entre outras). Assim, membros de uma determinada cultura organizam categorias particulares de maneira padronizada, porém, as maneiras pelas quais certas categorias são naturalmente agrupadas será sempre um questionamento empírico em cada caso (SPEIER, 1970, p. 205).

No caso de contextos institucionais escolares, podemos entender o próprio conceito de sala de aula como um dispositivo que abarca

\footnotetext{
${ }^{2}$ Utilizamos a sigla do termo em inglês: Membership Categorization Analysis.
} 
categorias como as de professor e aluno. Assim, outro aspecto levantado por Sacks é que algumas categorias podem: (1) formar pares categóricos, como terapeuta/paciente, professor/aluno; (2) em certos contextos, ser onirrelevantes, como terapeuta/paciente em uma sessão de terapia ou professor/aluno em uma sala de aula.

Esse aspecto da onirrelevância não significa que essas categorias estejam sempre operando, pois elas podem não se tornar relevantes na sequência da interação pelo seu próprio caráter naturalizado. Tampouco isso quer dizer que elas não possam ser subvertidas ou ressignificadas, quer dizer somente que podem se tornar relevantes a qualquer momento da interação, justamente pelo seu caráter onirrelevante naquele cenário específico. Ademais, no contexto de sala de aula, há também certas atividades ligadas a categorias ${ }^{3}$ (SACKS, 1972) que, de certa maneira, corroboram a onirrelevância do par professor/aluno.

Descrições prévias de salas de aulas (EGLIN, 2009; HUSTLER; PAYNE, 1982; MACBETH, 1991; SEEDHOUSE, 2004) mostram alguns padrões interacionais entre professores e alunos e como certas atividades podem ser definidoras do que é "ser professor" e do que é "ser aluno". Em muitos contextos, "a sociedade delega poder e autoridade aos professores, e em uma sala de aula é o professor que tem o poder e os alunos que são os subordinados na relação professor-aluno" (HUSTLER; PAYNE, 1982, p. 54). No entanto, para a ACE, não existe ordem que não seja a ordem local, dessa forma, mesmo que existam concepções externas consolidadas em relação a categorias de pertencimento relacionadas ao cenário estudado, elas não são definitivas e não substituem as ações e as interpretações dos participantes no "aqui e agora" da interação. Como colocado por Almeida (2009, p. 46): “os participantes de um encontro social mediado pelo uso da linguagem trabalham, na fala, as diversas identidades para si e para os outros, tanto como um fim em si mesmas, ou como um meio para atingir outros fins".

É importante mencionar que a tradição de pesquisa em MCA, apesar de também ter sua base na EM, desenvolveu-se de maneira independente da ACE (WATSON, 1997). Neste estudo, no entanto, analisamos o trabalho de categorização na sequência das interações nas atividades do curso de contação de histórias a partir da perspectiva analítica da ACE. Propomos,

\footnotetext{
${ }^{3}$ No original, category bound activities.
} 
assim, que não haja uma ruptura entre as duas abordagens (a MCA e a ACE) no momento da observação e análise dos dados, e sim uma integração entre elas.

\subsection{Instruções-em-ação}

Instruções-em-ação referem-se a outro fenômeno que aparece de maneira notória em nossos dados, o que não poderia ser diferente. Instruções são propriedades fenomenológicas de qualquer curso e segui-las é uma necessidade lógica para que o curso aconteça. A razão de tomarmos esse fenômeno como um objeto de nossa análise está na intenção de explorar algo que, por ser tão corriqueiro, comum e aparentemente "desinteressante" (GARFINKEL, 2002), escapa do olhar analítico, não sendo, assim, comumente discutido em trabalhos sobre interação em sala de aula em língua adicional até então.

Por serem massivamente presentes em qualquer ambiente institucional, instruções-em-ação poderiam ser fenômenos amplamente estudados. Garfinkel (2002) chama a atenção para o fato de que quando as instruções estão em forma de "produto", ou seja, escritas em um plano de curso ou no manual de um jogo de tabuleiro, elas podem ser lidas como diretrizes, regras ou comandos. Porém, quando as instruções são seguidas durante a interação, elas transformam-se em ações, ganham vida e significado. Por isso, se quisermos saber o que um plano de aula realmente significa, temos que analisá-lo com base nas ações das pessoas que fazem esse plano acontecer. Em outras palavras, são as pessoas, ou seja, os participantes de uma aula, que dão sentido às instruções, são eles que as testam, as interpretam, as "desafiam" e as produzem localmente, sempre como uma primeira vez, para todos os propósitos práticos (GARFINKEL, 1967, p. 9).

Explorar instruções-em-ação pode ser relevante para notarmos como a aprendizagem é evidenciada na interação. Majlesi e Broth (2012) mostraram como projetos de aprendizagem emergem e são ocasionados na (e através da) colaboração entre os participantes de uma sala de aula de língua adicional e, segundo os autores, esses projetos podem ou não fazer parte da agenda pedagógica do professor (MAJLESI; BROTH, 2012, p. 205). Sendo assim, é impossível descrever em um plano de ensino tudo o que pode ser seguido pelos membros de uma sala de aula. 
O plano pedagógico como um 'produto', um 'texto dócil' (GARFINKEL, 2002, p. 200) não prevê as particularidades que orientam as práticas em sala de aula. Essas particularidades (ou haecceities, como define Garfinkel) são apenas observáveis e inspecionáveis no plenum, ou seja, na complexa malha interacional das interações humanas, das práticas sociais.

\section{Metodologia e contexto do estudo}

Apresentaremos a seguir a nossa orientação metodológica e o contexto no qual os dados foram gerados. É importante notar que vamos discutir o trabalho de categorização realizado pelos participantes ${ }^{4}$ em um ambiente de ensino-aprendizagem e como esses participantes "transformam" instruções do curso em ações inspecionáveis na prática. Assim, esse tipo de orientação deve ser capaz de analisar elementos interacionais observáveis in situ, ou seja, que estão preservados nas gravações em áudio e vídeo que realizamos durante o curso. Mehan (1979) chama esses elementos interacionais de "dados recuperáveis" (retrievable data), uma vez que eles podem ser revisitados toda vez que quisermos confirmar/questionar a nossa própria análise.

\subsection{Análise da Conversa Etnometodológica}

Este trabalho se insere no campo de estudos denominado Análise da Conversa Etnometodológica (ACE). Essa tradição de pesquisa é um dos importantes desenvolvimentos da Etnometodologia, uma abordagem sociológica de cunho praxiológico, que surgiu a partir dos estudos de Harold Garfinkel (1976).

Em seu livro Studies in Ethnomethodology, Garfinkel apresenta reflexões que têm como tópico central "a explicabilidade racional das ações como uma realização prática e contínua"5 (GARFINKEL, 1967, p. 4), ou seja, os procedimentos rotineiros pelos quais os atores sociais fazem e interpretam o dia a dia: modos pelos quais os membros da sociedade produzem e prestam conta das ações em contexto. Assim, o termo Etnometodologia (EM)

\footnotetext{
${ }^{4} \mathrm{O}$ trabalho de categorização é assumido conjuntamente pelos participantes de uma interação. Desse modo, não há uma separação binária de "quem realiza" e "quem recebe" a ação de categorizar, pois, como definem Hester e Eglin (1997), categorias de pertencimento são cosselecionadas e mutualmente constitutivas de significado.

${ }^{5}[\ldots]$ the rational accountability of practical actions as an ongoing, practical accomplishment.
} 
designa o estudo da organização social, os métodos utilizados pelas pessoas para formular e atualizar a ordem local, para fazer sentido e demonstrar entendimentos nas e das atividades cotidianas, em interações sociais.

Deste modo, para entender as ações e as interações sociais, é preciso que os conhecimentos considerados "senso comum" sejam observados e analisados praxiologicamente. Em outras palavras, é necessário investigar a maneira que esses conhecimentos são expressos nas ações e práticas cotidianas produzidas pelos participantes (GARFINKEL, 1967; WATSON; GASTALDO, 2015) cujas interações estão preservadas nos dados coletados por meio de gravações audiovisuais.

A EM trata os participantes como os seus principais analistas. É a partir das orientações visíveis dos participantes ao que é dito ou feito na interação que o pesquisador tira conclusões a respeito do fenômeno investigado. Isso significa que a EM rejeita o uso de teorias e sistemas de codificações assumidas a priori. Essa rejeição (a qual Garfinkel dá o nome de "indiferença etnometodológica") caracteriza-se por uma abordagem metodológica em favor da observação radicalmente naturalista dos fenômenos sociais; abordagem que procura investigar como as pessoas produzem conhecimento no mundo, sem a necessidade de corroborar ou falsear teorias.

Tendo em vista que o conhecimento do mundo social é feito de normas e concepções e é expresso aos outros, em grande parte, através das palavras, a linguagem aparece como o mais importante veículo para troca desses significados e conhecimentos que constituem o mundo social (GARFINKEL; SACKS, 1970; WATSON; GASTALDO, 2015). Na esfera dessa busca por entendimentos sobre como se constituem as ações sociais, observou-se que há um certo uso da linguagem do qual todos nós participamos cotidianamente: a conversa.

Segundo Garcez (2008, p. 20) "a conversa cotidiana é a pedra fundamental da socialidade, e talvez só essa forma de fala-em-interação seja universal", ${ }^{6}$ assim, as outras formas de fala-em-interação possuem um caráter secundário e derivam da organização fundamental que é a da conversa.

\footnotetext{
${ }^{6}$ Lembramos aqui também da observação de Georg Simmel (citada em WATSON; GASTALDO, 2015, p. 88, parênteses e ênfase dos autores): “a conversa é a mais ubíqua, a mais precisa e singular das formas de socialização (hoje diríamos interação social)".
} 
Ao se analisar a conversa, observa-se a existência de o que Schegloff (1987) denomina de sistemas de trocas de fala. É dessa concepção linguística da vida social (GARFINKEL; SACKS, 1970) que se desenvolveu a ACE, que focaliza o modo pelo qual as pessoas (co)produzem a realidade pela fala-eminteração, noção que abarca as atividades vocais e não-vocais que constituem as interações sociais humanas (GARCEZ, 2006). Assim, os estudos em EM e ACE têm nos mostrado que atividades sociais de qualquer ordem podem ser estudadas olhando-se de perto, principalmente, para um dos principais constituintes de tais empreendimentos cotidianos: a fala (SPEIER, 1972).

É importante salientar que a análise das atividades vocais e não-vocais não deve ser realizada de maneira combinatória, como se as partes dessas atividades fossem produzidas isoladas de contexto e analisadas como peças de quebra-cabeças.

Garfinkel (2002), Wieder (1974), Gurwitsch (1964) e Liberman (2013) insistiram na ideia de que gestos e fala não são interpretados de forma separada, pois são elementos que fazem parte de uma mesma unidade, um mesmo gestalt. Quando nos referimos a gestalt, reforçamos que o contexto é produzido pelas ações práticas dos interagentes, que se tornam visíveis como um todo, em vez de fenômenos separados que operam uma limitada síntese racional de significados.

Exemplificando a ideia discutida, Aron Gurwitsch chama a atenção para o fato de que uma melodia não pode ser considerada como tal meramente pela soma das suas notas musicais. Da mesma forma, a estrutura organizacional das ações sociais não é exibida por itens isolados (fala + gestos, por exemplo), mas por uma relação intrínseca dos seus elementos. Segundo Gurwitsch (1964), isso seria uma "necessidade lógica".

O nosso foco, portanto, está nos elementos interacionais observáveis e inspecionáveis como um todo, ou seja, em entender como os membros da sociedade demonstram, por meio de suas ações, seguir a ordem moral e o curso dos afazeres diários: "O mundo da vida cotidiana conhecido em comum com os outros e com os outros tomado como garantido"7 (GARFINKEL, 1967, p. 35).

Adotadas por pesquisadores de diferentes áreas do saber, como a sociologia, a linguística e a comunicação, interessados em como as pessoas conduzem e levam a cabo ações do dia a dia, a EM e a ACE permitem

\footnotetext{
${ }^{7}$ the world of daily life known in common with others and with others taken for granted.
} 
investigar interações em cenários diversos, desde os mais cotidianos e corriqueiros, até os mais formais e padronizados.

Nas sociedades contemporâneas, aprendemos também a participar de usos da linguagem que são mais especializados, com modificações significativas, "de modo a restringir certas ações e facilitar outras" (GARCEZ, 2006, p. 67), se compararmos com o que ocorre na organização primordial da fala cotidiana (SACKS; SCHEGLOFF; JEFFERSON, 1974). Dessa forma, apesar de os estudos em ACE terem suas noções basilares fundamentadas na conversa cotidiana, entender como as pessoas interagem em contextos institucionais (hospitalar, escolar, jurídico, entre outros) também passou a fazer parte da agenda dessa tradição de pesquisa.

O presente estudo enquadra-se nessa gama de investigações que busca entender as organizações endógenas das interações em ambientes institucionais, mais especificamente os que enfocam a fala-em-interação em sala de aula. Cenários como esses são tão corriqueiros que muitas vezes não questionamos como são organizados, como chegamos àquela ordem e de que maneira ela se torna reconhecível e explicável pelos participantes. Assim, desde os primeiros desdobramentos da EM e da ACE, estudos visam a compreender e revelar a ordem interna, atualizada nas interações, de ambientes escolares.

A partir da perspectiva etnometodológica, para podermos compreender a lógica interacional racional de um curso de língua, é preciso olhar para como quem participa desse cenário faz - e lida com - as atividades que tornam esse curso de língua o que ele é, pois "a concretude do que seja a sociedade e as suas instituições (...) não está dada em elementos preexistentes e absolutos, mas no fazer conjunto das pessoas a cada dado momento em que se encontram para fazer o que precisam e desejam fazer." (ALMEIDA, 2009, p. 67). Assim, estudos etnometodológicos em contextos educacionais podem possibilitar uma compreensão mais profunda de diferentes aspectos relacionados a esses contextos, de como eles são localmente (re)organizados pelos participantes nas interações.

Desse modo, lançamos mão dessa abordagem metodológica para investigar uma interação do curso de contação de histórias ocorrida na China. O curso conta com algumas características marcantes em seu planejamento, como a interdisciplinaridade e uma metodologia de ensino e aprendizagem que integra o trabalho com literatura oral, performance e língua, com 
exercícios de corpo, voz, dinâmicas e jogos teatrais. Apresentaremos mais detalhes do curso a seguir.

\subsection{Contexto do estudo}

Consideramos importante apresentar o curso de contação de histórias pelo seu caráter interdisciplinar e por ser um contexto de sala de aula que se diferencia de contextos educacionais ditos mais tradicionais. Entretanto, salientamos que essa contextualização não pretende estabelecer nenhuma concepção apriorística sobre o tipo de interação que esse curso pode ou não ocasionar, mas sim situar esse curso no mundo a partir de seus objetivos e de sua elaboração.

De antemão, destacamos que a contação de história no curso é, na maioria das vezes, uma ação ensaiada, não espontânea. Assim, nosso interesse está principalmente em olhar para as interações em atividades que são subsequentes e que cercam o ato de (re)elaborar e (re)contar uma história, não a contação em si. Portanto, consideramos relevante que o leitor deste trabalho conheça o curso $^{8}$ e seus objetivos para que possa compreender as singularidades deste cenário.

A contação de histórias foi um curso elaborado por uma das autoras deste artigo e pela professora/pesquisadora Camila Dilli a partir de 2006, quando iniciaram a trajetória como contadoras de histórias ${ }^{9}$ e na área de PLA, em uma universidade no Brasil. Desde então, a ideia da realização de um curso que formasse contadores falantes de outras línguas, para contar histórias em português, foi sendo desenvolvida e, em 2009, foi materializada uma proposta de curso que foi aceita pelo Programa de Português para Estrangeiros da mesma universidade.

Desde o ano de 2010, a contação de histórias passou a integrar o quadro de disciplinas desse programa e, no total, foram realizadas 11 edições do curso nesse contexto. O curso foi oferecido pela primeira vez fora do Brasil em 2017, em uma universidade em Macau e, logo em seguida, em uma

\footnotetext{
${ }^{8}$ Para informações mais detalhadas sobre o curso, ver Dilli e Morelo (2019).

${ }^{9}$ Ano em que participaram de um grupo de contadores parte de um Projeto de Extensão que objetiva oportunizar aprendizagens em atividades extracurriculares e que, através do ato de contar histórias, visa estimular a leitura, o resgate da identidade cultural e a prática da cidadania.
} 
universidade no interior da China, ${ }^{10}$ ambas as ofertas na modalidade de curso extracurricular ${ }^{11}$ e para os Departamentos de Português.

Os dados que serão apresentados neste estudo foram gerados na edição do curso de contação de histórias realizada no interior da China, que ocorreu de fevereiro a junho de 2017. Os dados foram gravados em vídeo e o excerto apresentado neste texto foi retirado de uma das aulas do curso e transcrito para a análise. O encontro no qual ocorreu a interação analisada teve cerca de duas horas e vinte minutos de duração (2:22:05) e cinco participantes (Luna, Nubia, Talita, Adriana e Jéssica). ${ }^{12}$ Todas as participantes são do sexo feminino. ${ }^{13}$ As estudantes estavam no segundo ano de uma graduação em Letras-Português de uma universidade chinesa e possuíam um nível de língua próximo ao intermediário.

Embora os dados deste artigo sejam do curso realizado no interior da China, o que ocorreu em Macau já foi foco de uma pesquisa (CHEN, 2018), na qual a autora estudou como os participantes do curso usavam práticas de reparo ${ }^{14}$ para manter a intersubjetividade durante as atividades. Além dos apontamentos levantados pela autora em relação ao tópico enfocado, as descrições e análises dos excertos selecionados por Chen (2018) também trouxeram observações importantes que corroboram a nossa análise dos dados em relação às formas de participação no curso e às categorias de pertencimento acionadas pelos participantes. A autora indica que há uma relação entre os participantes que parece menos assimétrica se comparada

\footnotetext{
${ }^{10}$ A expressão "Interior da China" equivale ao termo Mainland China em inglês, ou seja, refere-se à parte continental da China, excluindo as suas regiões insulares como Macau e Hong Kong.

${ }^{11} \mathrm{O}$ curso também já foi ofertado, em formato de oficina, em uma universidade na Dinamarca.

${ }^{12}$ As participantes são identificadas por pseudônimos.

${ }^{13} \mathrm{O}$ curso foi oferecido como atividade extracurricular e divulgado em um programa de Letras de uma universidade chinesa, onde a maioria dos alunos era de sexo feminino. Isso parcialmente explica a presença de apenas mulheres no curso.

${ }^{14}$ Reparo refere-se a práticas que os participantes de uma interação usam para identificar e lidar com dificuldades perceptíveis na comunicação, como problemas de entendimento, informações equivocadas, dificuldade na articulação de palavras etc. O estudo precursor das práticas de reparo foi publicado por Schegloff, Jefferson e Sacks (1977), mas estudos posteriores colaboraram para um maior entendimento do fenômeno (SCHEGLOFF, 1992, 2000). Recentemente, outros estudos analisam práticas de reparo em ambientes interacionais para além da conversa, como em jogos de mímica (CHEN, 2018) e manipulação de personagens na tela do computador (GREIFFENHAGEN; WATSON, 2009).
} 
à que é comumente encontrada em ambientes educacionais. Trata-se, mais amplamente, da produção e divisão conjunta do poder em sala de aula, conforme explica a autora:

Um fato importante de ser ressaltado é o de ser a professora que detém mais conhecimento a respeito das atividades realizadas nas aulas. Sendo assim, ela deveria ter subsídios (recursos interacionais) que pudessem "decidir" o que seria realizado a seguir. Contudo, (...) ilustra-se o momento em que a professora não é a única detentora do poder neste cenário. Ao contrário, ela compartilha a responsabilidade com os alunos, que frequentemente interrompem as falas dela para indicar e resolver os problemas. (CHEN, 2018, p. 59)

Destaca-se, então, que todos os participantes passam a fazer parte da definição das regras da atividade, como um grupo que é conjuntamente responsável pela manutenção da intersubjetividade da aula. Segundo Chen (2018), isso quer dizer que a professora, em certos momentos, não é caracterizada com o estatuto de "participante mais competente" a respeito de um assunto. Conforme já mencionamos, esse aspecto em relação ao curso diferencia-se do que comumente é encontrado em ambientes educacionais centrados na figura do professor como único detentor do saber.

O compartilhamento de responsabilidades pode ser observado como uma meta medular no planejamento do curso de contação de história. A formação de um grupo de contadores, conforme será relatado posteriormente, é uma das bases para o desenvolvimento das atividades do curso, assim, para a formação de tal grupo, seria esperado que essa hierarquia entre professor e alunos fosse minimizada nesse cenário. No entanto, a atualização dessas metas, no momento aula, pode ocorrer de diversas maneiras no "aqui e agora" da interação - podendo, inclusive, não ocorrer -, e é isso que queremos observar.

É importante destacar, por seu caráter interdisciplinar, como o ensino de português entra no planejamento do curso de contação. O trabalho com as estruturas linguísticas está a serviço do objetivo de ensino central do curso: contar histórias, ou seja, a visão de linguagem que está por trás das atividades é a de que a língua é usada para agir no mundo, "para fazer coisas” (CLARK, 2000, p. 49). É essa concepção que também motiva o trabalho através de um projeto pedagógico, pois ele visa a possibilitar que os participantes vivenciem e aprendam coletivamente, nas diferentes etapas 
do curso, recursos - linguísticos, vocais, corporais e cênicos - para poderem, conforme o andamento das aulas, gradualmente, tomar decisões em relação a sua performance e contribuir com a do colega.

Conforme apontam Dilli e Morelo (2019), ao definir os objetivos de ensino e aprendizagem para um curso de língua que se destina à oralidade, é preciso considerar que não há "capacidades orais independentes das situações e das condições de comunicação em que se atualizam" (SCHNEUWLY, 2004, p. 136). Assim, desde o início do trabalho de busca por histórias e de planejamento das rodas de contação, os participantes são orientados quanto à adequação de sua produção oral: "Saber falar, não importa em que língua, é dominar os gêneros que nela emergiram historicamente, dos mais simples aos mais complexos" (SCHNEUWLY, 2004, p. 138).

Independentemente do nível de proficiência do participante, estudar um gênero discursivo significa aprender o que é relativamente estável dentro desse gênero (BAKHTIN, 2003) e, na produção, aplicar esse conhecimento e fazer escolhas informadas, neste caso, em relação a cada história escolhida e contação elaborada. Apresentam-se, então, como importantes elementos para a compreensão do gênero discursivo em questão, as condições de produção e interlocução projetada:

Desde o primeiro dia de aula, é explicitado a todos que o
objetivo final é contar uma história de maneira performática,
em uma roda de contação, para um público específico, externo
à sala de aula, não só para colegas e professoras. Essa escolha
de um público externo se relaciona ao trabalho direto com
as condições de produção e recepção do gênero do discurso
oral enfocado. Quem conta o faz para alguém, adapta a sua
história aos interlocutores presentes e aos que chegam, bem
como sua performance ao local, à sua acústica e dimensão. A
história contada é parte de um todo, que envolve o outro, o
espaço, o tempo e todos os aspectos implicados na imediatez
da interação face-a-face, tudo isso é a história. (DILLI;
MORELO, 2019, p. 94)

Deste modo, temos um curso que trata de um gênero discursivo específico (contação de histórias), que também é massivamente presente no nosso dia a dia (LUKE, 2016; TABENSKY, 2012; WATSON; IRWIN, 1996). "O estudo da realização do que é mundano muitas vezes pode iluminar aspectos de preocupações educacionais mais amplas de maneiras 
inesperadas"15 (PAYNE; CUFF, 1982, p. 3). Portanto, uma sala de aula - e o estudo sobre ela - em que o ensino e aprendizagem é focado em gêneros utilizados no nosso dia a dia é um cenário para ampliarmos nossos entendimentos dos fazeres educacionais.

\section{Análise dos dados gerados no curso de contação de histórias}

Apresentaremos a nossa análise dos dados em duas partes, de acordo com os fenômenos que vamos explorar em cada uma delas. Pedimos aos leitores para lerem o excerto completo, que pode ser encontrado no Apêndice 2. Vamos, porém, recuperar partes do excerto (que chamaremos de "seguimentos"), ao longo de nossa discussão, quando nos referirmos a algum trecho específico em nossa análise.

\subsection{Fazendo sentido das instruções}

Antes de chamar a atenção para alguns pontos específicos, consideramos importante esclarecer a natureza da atividade que estava em andamento no momento em que os dados foram gerados, antes de entrarmos no excerto apresentado. Essa atividade se trata de uma dinâmica bastante presente no desenvolvimento do curso de contação de histórias. Depois que um participante conta sua história ${ }^{16}$ pela primeira vez, ele fica parado na frente dos outros participantes, para responder perguntas em relação à história que contou e também ouvir comentários sobre a história e a performance.

A instrução dessa tarefa é conhecida pelas participantes do encontro, que já entraram em contato com essa atividade em aulas anteriores. Sendo assim, neste encontro, não houve uma formulação explícita da instrução da tarefa por parte de nenhuma participante antes que Talita começasse a contar. As participantes também já haviam entrado em contato com o material impresso do curso (uma apostila) e já tinham tomado conhecimento em outro momento da tarefa "Imaginando a performance", que visa a instruir os participantes a ajudarem o contador a melhorar a sua história.

\footnotetext{
${ }^{15}[. .$.$] study of accomplishment of the mundane can often illuminate aspects of wider educational$ concerns in unexpected ways.

${ }^{16}$ Aqui nos referimos a história escolhida para a contação final, que, geralmente, pertence à tradição oral do país do estudante.
} 
No entanto, nesta interação, apesar de algumas participantes estarem com materiais no colo, em nenhum momento elas direcionam seus olhares para os materiais impressos. O que temos neste excerto, então, é a instrução-em-ação (GARFINKEL, 2002), ou seja, uma concretização dessa instrução na condução da atividade pelos interagentes, que estão produzindo conjuntamente o contexto do curso, já que o contexto, na perspectiva da EM e da ACE, é a conduta dos participantes (SACKS, 1976; HERITAGE, 1984).

Isso significa dizer que é na ação (na tarefa desempenhada pelos membros sociais) que as instruções fazem sentido e tomam corpo. É neste ponto em que as participantes começam a transformar diretrizes em fenômenos de ordem (GARFINKEL, 1967, 2002), visíveis na interação. As regras são ouvidas, lidas, interpretadas, avaliadas e reflexivamente aplicadas na interação, elas são a interação, pois não há interação sem ordem (GARFINKEL, 1967; GARFINKEL; SACKS, 1970).

A formulação deste contexto de caráter único já pode ser observada no Segmento 1. Após a contação de Talita, o primeiro turno é de Luna, que faz um comentário apreciativo sobre a história: "que história bonita". Depois de uma pausa de um segundos e nove décimos, questiona se alguém tem alguma pergunta, movimentando seu corpo para a frente e direcionando o olhar primeiro para a direita (FIGURA 1) e depois para a esquerda (FIGURA 2), olhando para as participantes que estão sentadas ao seu lado.

Um primeiro ponto é a própria pergunta de Luna: "alguém tem alguma pergunta?”, dirigida às participantes que se encontram como plateia. Essa pergunta, em contextos educacionais geralmente é feita pelo participante categorizado como professor, com o propósito de verificar respostas e entendimentos de outros participantes, tradicionalmente categorizados como estudantes.

Conforme apontado por Macbeth (2000, p. 28): “Questionar a classe, por exemplo, é um formato massivo de instrução em sala de aula, e as organizações do discurso literalmente materializam o ensino e o aprendizado que acontecem lá”. ${ }^{17}$ No entanto, neste caso, a pergunta de Luna não é dirigida a todos os participantes, é dirigida à plateia, o que pode ser percebido pelo direcionamento de olhar da participante, que olha para os lados, local em que a plateia está, o que não inclui Talita, que acabou de contar a história

\footnotetext{
${ }^{17}$ Questioning the class, for example, is a massive format of classroom instruction, and organizations of discourse literally materialize the teaching and learning that goes on there.
} 
e está de pé em frente à plateia. É possível observar esse fenômeno abaixo, quando recuperamos apenas o trecho referido.

Segmento 1: Olhar de Luna para a plateia e intervenção de Nubia (linhas 1-11):

\section{Luna :}

02

2

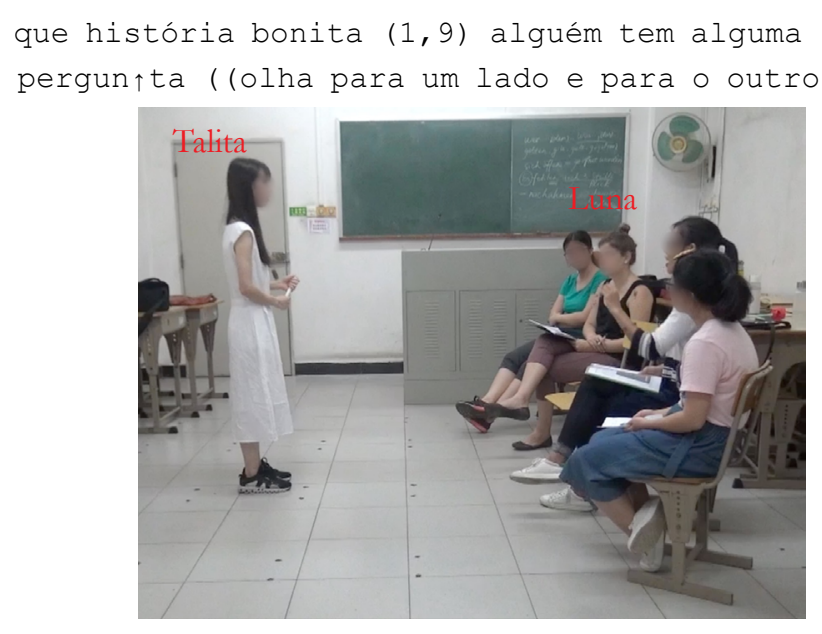

Figura 1
03

04 Nubia: 05

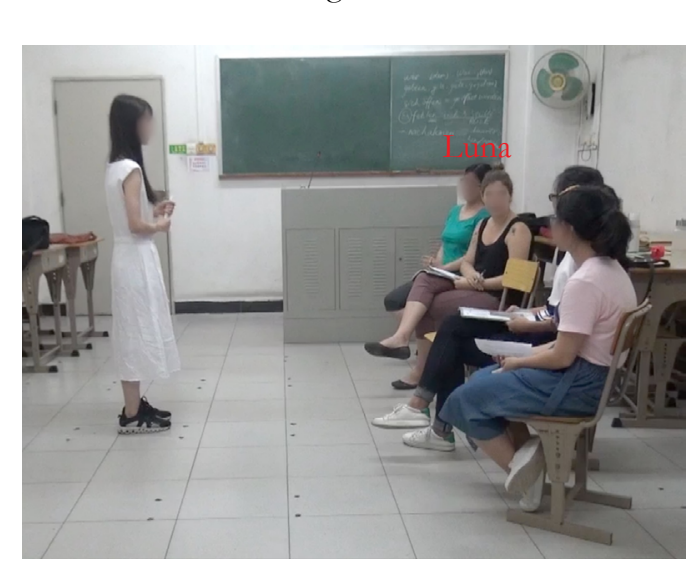

Figura 2
$(1,8)$

$$
\begin{aligned}
& \text { ã:: (.) ã:: (.) no início (.) cê: ã: disse eles } \\
& \text { ã:: tem o:: ã compromisso= }
\end{aligned}
$$




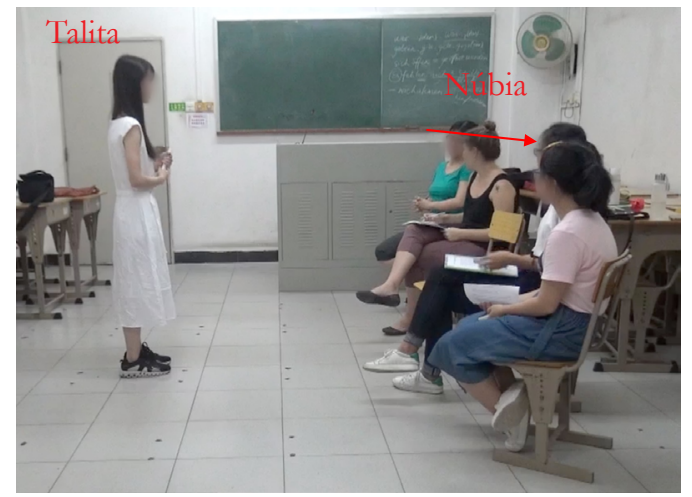

Figura 3

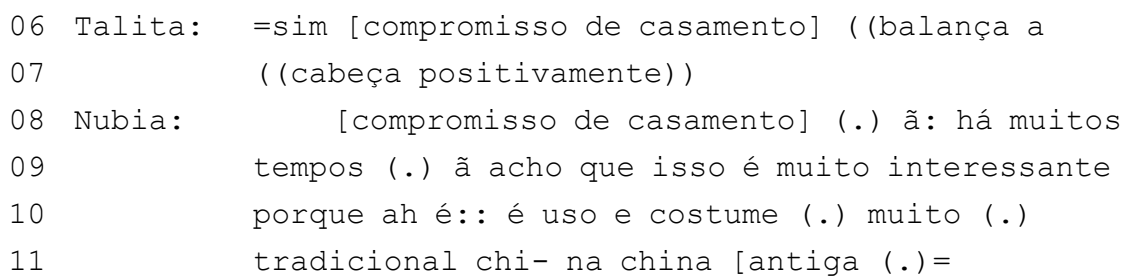

Assim, a pergunta de Luna, na verdade, é se alguém tem alguma pergunta para a Talita sobre a história, pois Talita é a contadora e apresentou sua história no curso pela primeira vez para aquela plateia, ou seja, ela é a participante com conhecimento sobre a história. Ao longo da interação fica evidente que Luna não teria informações para responder perguntas sobre a história que acabou de ser contada, ou seja, caso alguém tomasse o turno após a pergunta de Luna, para fazer uma pergunta, o turno seria direcionado a Talita (como ocorre posteriormente). Tal dinâmica contraria o que comumente acontece em uma sala de aula: o professor pergunta se alguém tem uma pergunta, se um aluno faz uma pergunta, em geral, é o professor quem responde.

O fato de ser Luna a primeira participante a tomar o turno após a contação e a fazer essa pergunta para os outros participantes, e não Talita, nos indica que Luna é a participante responsável pela coordenação das ações em curso, o que invoca a categoria de professora do curso para Luna. Temos aqui, portanto, mais um exemplo de instrução-em-ação, em que 
as diretrizes do curso (p.e. quem é a professora, ${ }^{18}$ quem tem o direito de perguntar e de responder etc.) somente tomam sentido na sua realização, pois é na realização que elas acontecem, como se fosse sempre uma primeira vez, para todos os propósitos práticos.

Depois que Luna faz a pergunta, ocorre um silêncio de um segundo e oito décimos, assim, Nubia (linhas 4 e 5) inicia um turno marcado por pausas e alongamento de vogais, o que pode indicar hesitação, dúvida ou, ainda, a procura por vocabulário adequado. Ela fala sobre o início da história contada por Talita, sobre o compromisso, o que, em seguida, é confirmado por Talita (linha 6), que afirma "sim" e complementa com "compromisso de casamento", sobrepondo sua fala a de Nubia, que também especifica o tipo de compromisso quando rapidamente retoma o turno. Nubia mantem o olhar direcionado a Talita durante toda sua intervenção (FIGURA 3) e continua o seu turno (linhas 8, 9,10 e 11) afirmando que acha essa questão (o compromisso de casamento) algo muito interessante - quando faz essa afirmação, ela inclina seu corpo para a frente (FIGURA 4) e produz uma justificativa para essa opinião, dizendo que é um costume muito tradicional. Neste momento, Nubia inicia uma caracterização do costume que está descrevendo e produz um autorreparo de sua fala na linha 11: "é uso e costume muito tradicional chi na china antiga".

Sendo assim, entre as linhas 4 e 11, Nubia conduz a ação de fazer um comentário apreciativo sobre o costume que aparece no início da história contada por Talita e, posteriormente, conforme podemos observar no excerto completo, ela justifica o comentário e sugere que Talita conte mais detalhes sobre essa tradição.

Todas essas ações realizadas nos turnos de Nubia são ratificadas por outras participantes, inclusive por Talita, com demonstrações

\footnotetext{
${ }^{18}$ Aqui não queremos dizer que os participantes não sabiam quem era a professora do curso com antecedência, mas sim que há ações (ou 'predicados', segundo WATSON, 1997) atrelados a certas categorias (como 'professora' e 'alunos') que são acionadas no momento da interação; e não por imposição de normas institucionais (como normas da escola, por exemplo). Categorias, portanto, não são como símbolos lexicais, ou seja, assumidas naturalmente por uma "'maquinaria social" ou por um conhecimento de estruturas pré-existentes (como inicialmente propôs SACKS, 1995). Categorias fazem sentido na interação, de modo que, o analista (ao olhar para os dados gravados em vídeo) também é capaz (por ser um membro social competente) de associar a mesma categoria assumida pelos participantes a ações específicas realizadas por eles. Watson $(1997$, p. 62) chama esse fenômeno de "dupla reflexividade".
} 
de concordância através de sorrisos e do gesto de balançar a cabeça positivamente. É observável, então, que Nubia não fez nenhuma pergunta, contrariando o que seria esperado em termos de adjacência, levando em conta o turno de Luna (linhas 1 e 2). No entanto, não há nenhuma orientação das participantes para a ação de Nubia como equivocada ou inesperada, a ação dela é aceita, ratificada pelas participantes, pois ninguém corrige ou repara a fala de Nubia. Pelo contrário, algumas participantes se alinham aos turnos de Nubia e é a partir do comentário dela que outras ações se desenrolam na interação.

Nesse sentido, as participantes demonstram a produção conjunta do contexto, tendo em vista que em cada cenário os participantes "julgam os comportamentos e ações dos outros como apropriados ou não, relevantes ou não, em termos de sua relação com atividades tidas como necessárias para se atingir a meta definida tácita e situadamente nesse encontro" (GARCEZ, 2006, p. 68). Uma possível explicação para o turno de Nubia é o momento de silêncio que ocorre antes de seu turno, a participante pode ter interpretado que não havia perguntas e passou para uma próxima ação. Uma pausa de um segundo e oito décimos é uma pausa longa e, em muitas ocasiões, podemos considerar silêncios como turnos, como um objeto internacional (MACBETH, 1991, p. 288). Há, também, conforme mencionado, o fato de que Nubia já conhece as instruções em relação a essa atividade (fazer perguntas e comentários ao contador), desta forma, a ação dela simplesmente atualiza em ação as instruções conhecidas, deixando visível na interação que a participante está fazendo algo que é esperado e permitido dentro deste cenário.

Podemos observar, com base nos dados analisados, como as participantes desse curso mostram competência em fazer as regras tomarem sentido e, consequentemente, fazer o próprio curso acontecer. Essa competência não está apenas associada a um conhecimento meramente linguístico, afinal, saber agir no mundo em uma língua adicional é mais do que somente entender e produzir frases gramaticalmente corretas. Esse tipo de interação também exige saber produzi-las de uma maneira que os interlocutores possam produzir sentido daquilo que ouvem, que possam categorizar quem fala como membro pertencente àquele grupo social (neste caso, membros de um curso de contação de histórias) e contextualizar aquilo que está sendo dito como algo lógico e racionalmente ordenado. 


\subsection{A produção colaborativa de enunciados}

Na sequência da interação, após um turno de Luna (linha 18), ocorre uma micro-pausa e, então, Nubia (linhas 20-22) toma o turno outra vez e retoma o que parece ser uma explicação mais detalhada para a sugestão dada anteriormente. Seu turno é composto por pequenas pausas e pela produção alongada da vogal nasal [ã] diversas vezes, como também a de outros sons. Vejamos a recuperação deste trecho abaixo:

Segmento 2: Procurando palavras (linhas 20-27)

20

22

Nubia: ã:: na china antiga quando ã::m (.) ã: os amigos

ã: os ami- ã: o: : as (.) as ((coloca a mão no queixo e olha para cima)) as=

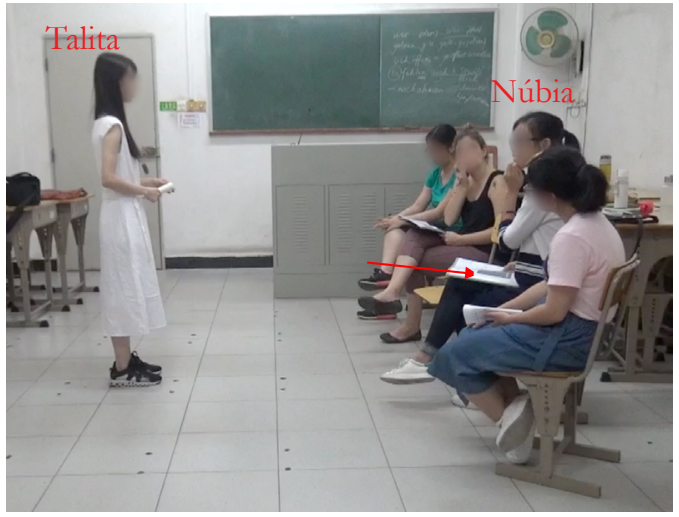

Figura 5

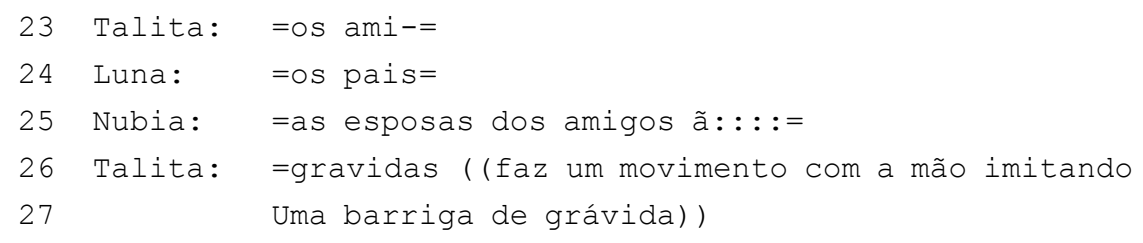




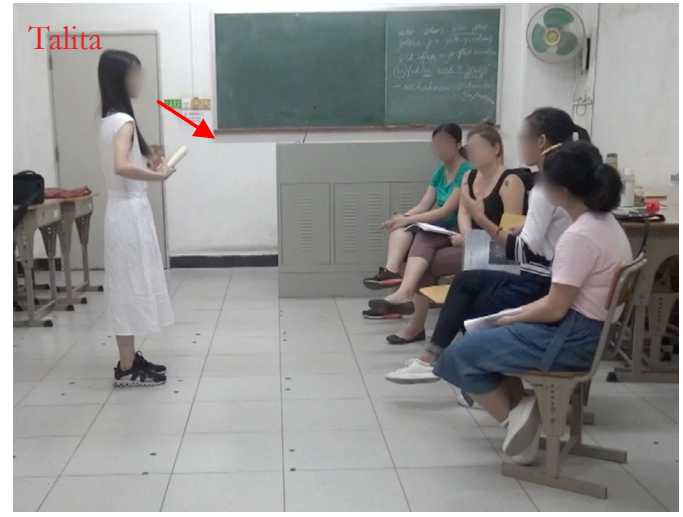

Figura 6

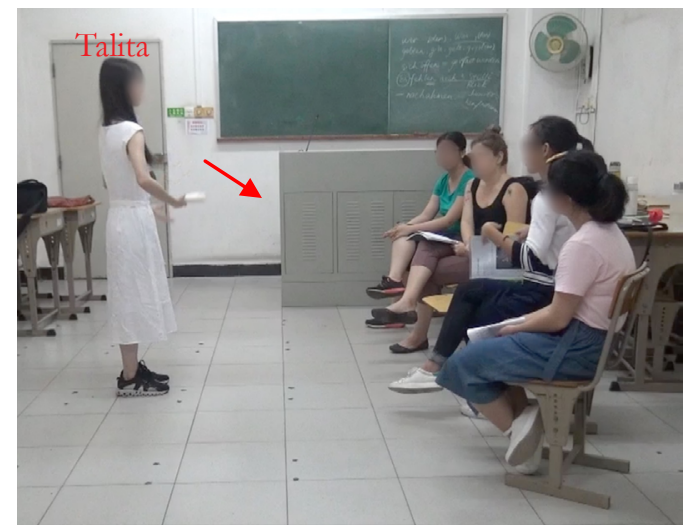

Figura 7

28 Nubia: =a: gra: são gra-grávidos no mesmo tempo eles 29 ã:m $(1,0)$ ã:m ((faz movimento com uma das mãos))

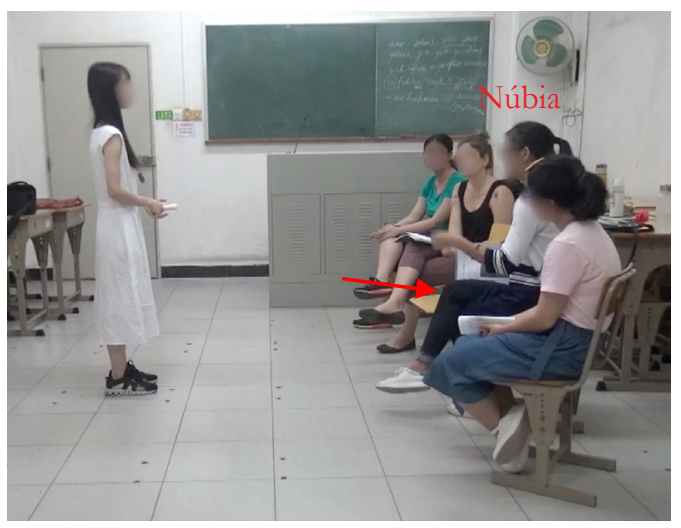

Figura 8 


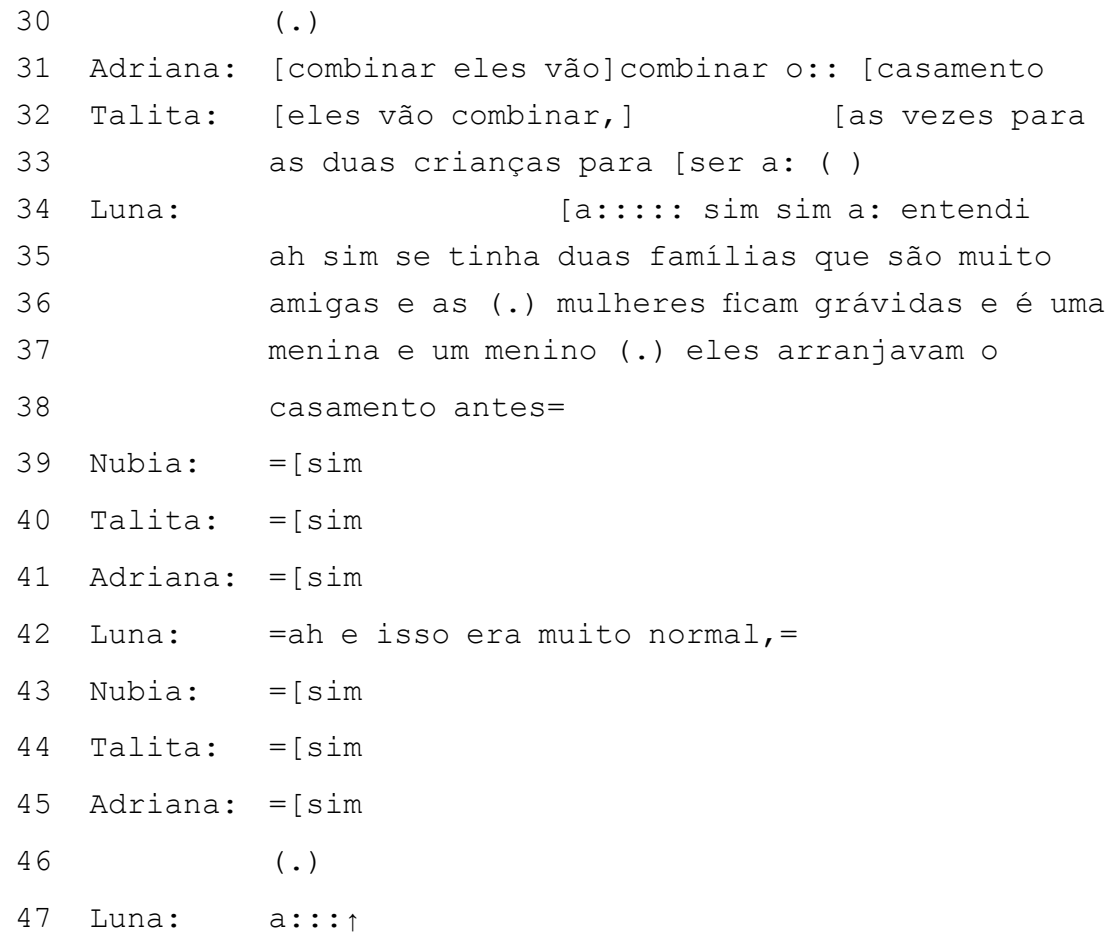

No turno em questão (linhas 20-22), Nubia dá mais indicações de que essas características composicionais do seu turno se dão pela procura de palavras. A participante inicia o turno dizendo "na China antiga os amigos", mas não prossegue, há hesitação e a repetição das duas primeiras sílabas da palavra amigo, interrompida de forma abrupta, seguida da repetição de itens, como "o", "as" e do gesto de colocar a mão no queixo ao mesmo tempo que realiza um movimento com a cabeça para o outro lado, mudando seu direcionamento de olhar (FIGURA 5).

Todas essas características do turno de Nubia indicam que ela está buscando itens lexicais para completar o seu raciocínio com sucesso, o que é percebido por outras participantes, que se orientam para o turno de Nubia e iniciam um trabalho de elaboração conjunta do comentário (uma formulação sobre o compromisso de casamento), através de ofertas de ajuda (BULLA, 2007; SALIMEN, 2009) de itens lexicais. Talita (linhas 23 e 26) e Luna (linha 24) passam a produzir palavras candidatas a compor a fala de Nubia, que podem vir a ser aceitas ou rejeitadas (SACKS, 1995, p. 321). Talita (linha 
23) inicia a ação de tentar ajudar Nubia a elaborar sua explicação, ela repete o início do item lexical "amigos", produzindo também as duas primeiras sílabas da palavra.

Na sequência do turno de Talita, Luna (linha 24) toma o turno e sugere "os pais". Nubia (linha 25) retoma o turno e segue com sua explicação, dizendo "as esposas dos amigos", utilizando um novo item (esposas), mas, em seguida, produz a vogal [ã] de forma bastante alongada, indicando que não tem certeza de como continuar seu turno. Porém, não utiliza o item sugerido por Luna (os pais). É possível perceber, mais adiante na interação, que Luna é uma participante que não tem amplo conhecimento do costume que está sendo descrito e explicado, então sua oferta de ajuda, na realidade, tinha muitas chances de não ser adequada e ser rejeitada por Nubia. Assim, notamos que o par categórico "conhecedor/não conhecedor" se torna relevante nesta interação, pois, para poder participar da elaboração do comentário de Nubia, era preciso conhecer tal costume que ela tentava descrever.

Talita (linhas 26 e 27) continua na tentativa de colaborar na formulação de Nubia e sugere outro item lexical: "as grávidas", e faz um movimento com a mão e com os braços, imitando a barriga de uma grávida (FIGURAS 6 e 7). Desta vez, Nubia (linha 28) aceita a ajuda de Talita e utiliza o item lexical sugerido pela colega para seguir com sua explicação sobre o compromisso de casamento e, após algumas oscilações no início do turno, ela diz "são grávidos ao mesmo tempo" e continua o turno com novas pausas, uso da vogal nasal [ã] (linha 29), e faz um movimento rápido circular com uma das mãos (FIGURA 8), o que indica novamente indecisão ou busca em relação aos próximos itens lexicais a serem usados para finalizar seu turno. Após uma micro-pausa, o trabalho colaborativo de produzir uma formulação do costume continua. No entanto, desta vez, Adriana (linha 31) e Talita (linhas 32 e 33), em vez de ofertar itens lexicais, completam o turno de Nubia.

As duas participantes dão continuidade ao enunciado que Nubia havia começado, e isso é perceptível inclusive na flexão de pessoa e número do verbo - terceira pessoa do plural - utilizada nos turnos. No turno de Nubia (linha 28) ela diz: "são grávidos no mesmo tempo eles" e a frase fica em aberto. Adriana e Talita produzem com falas sobrepostas a continuidade da frase: "combinar eles vão combinar o casamento" e "eles vão combinar", respectivamente, e Talita continua "às vezes para as duas crianças para ser a”, com a última parte do seu turno estando inaudível. 
Neste momento, ao final do turno de Talita, Luna (linhas 34-38) toma o turno em sobreposição e demonstra entendimento da explicação sobre o acordo de casamento, iniciando seu turno com o alongamento da vogal "a" (linha 34), seguida de "sim, sim, a entendi" e, em seguida, formula seu entendimento (GARFINKEL; SACKS, 1970; SACKS, 1976) com algumas micro-pausas ao longo de seu turno. Luna faz uma reformulação da explicação oferecida em conjunto pelas outras participantes para confirmar seu entendimento de que o costume se constituía em: quando duas famílias eram amigas, e as mulheres ficavam grávidas na mesma época, e os filhos eram uma menina e um menino, combinava-se o casamento deles.

Logo após o turno de Luna, Nubia, Talita e Adriana (linhas 39, 40, 41) se alinham à formulação da participante e ratificam, com falas sobrepostas, que o entendimento dela em relação à tradição chinesa está correto. Na linha 42, Luna produz outra formulação, para confirmar seu entendimento sobre a tradição, em relação ao fato de esse costume ser comum no passado, o que mais uma vez é confirmado pelas mesmas três participantes em uníssono, nas linhas 43, 44 e 45. Ocorre, então uma micro-pausa e Luna (linha 47) produz a vogal "a" de forma alongada, o que demonstra seu entendimento e uma mudança de status informacional (SCHEGLOFF, 1991). É interessante notar que as ações de Luna tornam evidente que ela é uma participante que não conhecia o costume que está sendo explicado. Neste momento, parece que todos chegaram a um entendimento compartilhado em relação ao que Nubia - e, posteriormente, também outras participantes - estavam tentando explicar.

A sequência de ações das linhas 20 até 47 revela um requintado trabalho colaborativo entre algumas participantes. Esta cooperação para chegar a uma formulação acurada do costume em questão é também informada pelo trabalho de categorização e pela produção conjunta do contexto. Conforme já apresentado anteriormente, em seu planejamento, uma das metas centrais do curso de contação de histórias é formar um grupo de contadores, no qual participantes se ajudam e colaboram uns com os outros em uma parceria para que todos cheguem à melhor versão de suas histórias e de suas performances. Novamente, portanto, temos aqui as diretrizes do curso tomando corpo, ganhando vida e fazendo sentido na fala das participantes.

Outro ponto interessante no trecho aqui explorado é a produção de enunciados em conjunto. Em uma de suas palestras, Sacks (1995) trata da 
produção conjunta de enunciados. $\mathrm{O}$ autor, após analisar alguns trechos de conversas em que pessoas completavam frases umas das outras, ou ofereciam sugestões de itens lexicais, conclui: "Provavelmente, não há maneira melhor de apresentar o fato de que 'somos um grupo' do que construir uma nova frase juntos, uma frase que seja coerente, gramatical etc.; e não planejada. Sua produção envolve, muito acentuadamente, uma atenção muito muito próxima e rápida à conversa um do outro"19 (SACKS, 1995, p. 322).

Speier (1972, p. 425), ao retomar Sacks (1995), explica que essa produção conjunta de um enunciado é um método categorizacional utilizado por pessoas que, conversando juntas, falam com a unidade de um grupo ajustando o discurso um do outro com rapidez, o que sugere o poder dos interagentes em realizar uma análise contínua das declarações um do outro, a fim de ajustar seu discurso com cuidado.

Assim, podemos, através da observação e análise do excerto, perceber ações das participantes que as constituem como um grupo e que mostram uma orientação para o pertencimento a um grupo de contadores de histórias através de suas ações (fazer comentários sobre a história da colega, dar sugestões, explicar as sugestões e ajudar umas às outras a formular todas as ações anteriores). Em outros estudos sobre interação em sala de aula, como Tabensky (2012), ao analisar a contação espontânea de uma narrativa pessoal em língua adicional, também são reveladas interações em que os participantes se orientam para uma conversa colaborativa para se atingir uma meta específica na língua em foco. Moutinho (2019) também apresenta e analisa um excerto em que, em um dado momento da interação, através de instruções da professora, é possível perceber o trabalho produzido conjuntamente por alguns estudantes, na ação de ajudar um participante a produzir um enunciado e atingir uma meta na língua adicional (KANITZ; FRANK, 2014).

Na sequência do excerto, após a demonstração de entendimento de Luna, há um lugar relevante para transição de turno, assim, Talita (linhas 48 e 49) toma o turno para oferecer mais detalhes sobre o costume e comenta que essa tradição aparece muito na literatura clássica chinesa, que é algo

\footnotetext{
${ }^{19}$ There probably isn't any better way of presenting the fact that 'we are a group' than by building a new sentence together, one that's coherent, grammatical, etc.; and unplanned. Its production involves, very markedly, a very very close and quick attention to the talk of each other.
} 
muito normal. Vejamos como isso acontece recuperando abaixo esta parte do excerto:

Segmento 3: Adaptando a contação ao público-alvo

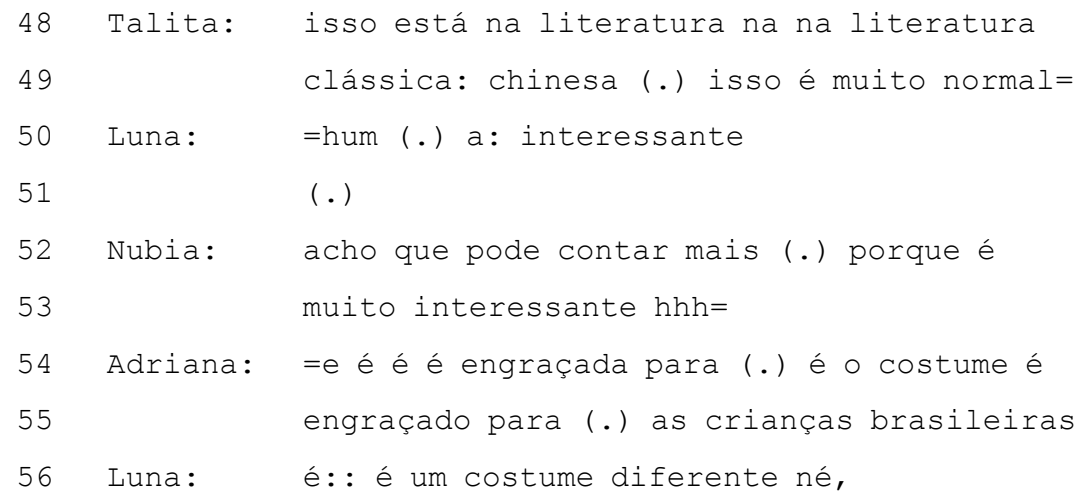

Após um novo comentário apreciativo de Luna (linha 50), Nubia (linhas 52 e 53) retoma a sugestão dada a Talita: "acho que pode contar mais porque é muito interessante", proferindo também uma risada. Adriana (linhas 54 e 55) ratifica o turno de Talita, afirmando que "é engraçada", que "é o costume engraçado para as crianças brasileiras", e Luna (linha 56) também se alinha aos comentários anteriores, produzindo uma afirmação através de um "é" alongado e do comentário que caracteriza o costume como diferente.

Estamos, assim, diante de um outro elemento central para nossa análise: nesta fase do curso, as participantes já sabem para quem vão contar as histórias na roda de contação final, já conhecem o público externo para o qual vão se apresentar: crianças brasileiras em uma escola. ${ }^{20}$ Nesse sentido, quando ocorre o turno de Adriana, que evidencia essa informação, ou seja, se orientando para essa interlocução para justificar por que (e, mais ainda, para quem) o costume é interessante, engraçado e diferente, tomamos conhecimento de uma informação muito relevante.

\footnotetext{
${ }^{20}$ A escola em questão foi fundada por e para uma comunidade brasileira em uma cidade da província de Guangdong, no sul da China. Ela segue o currículo brasileiro e o português é a língua veicular de instrução.
} 
Quando temos acesso a essa informação, é possível perceber que praticamente toda a interação estava orientada por e para esse aspecto: a interlocução projetada. ${ }^{21}$ Ao analisar os turnos de Nubia, há também a presença desse elemento: o costume é interessante (para alguém), o fato de ser uma tradição da China antiga o torna mais interessante ainda (para esse alguém). Assim, Talita deve falar mais sobre isso para as crianças brasileiras, uma categoria qualificada - temos estágio de vida e nacionalidade representados nessa categoria. No entanto, parece ser o dispositivo públicoalvo que aciona essas categorias na interação, a interlocução - o recipient - da apresentação final.

Boa parte da argumentação sobre a razão de o costume ser interessante parece estar conectada a essa categorização do interlocutor e a suas atividades ou características, como não conhecer bem os costumes tradicionais da China. Assim, temos duas categorias operando fortemente na interação (um par categórico), que parecem fornecer contexto para a sequência analisada: o grupo de contadoras, conhecedoras dos costumes tradicionais da China, e as crianças brasileiras, interlocutores que os desconhecem e que podem vir a achar certas tradições interessantes e engraçadas. Podemos, assim, observar aqui elementos culturais em ação na produção de predicados às categorias "grupo de contadoras" e "crianças brasileiras". Esses elementos acontecem no fazer, na interação, pois é nela que os elementos culturais fazem sentido: são a “cultura-em-ação" (HESTER; EGLIN, 1997).

\section{Considerações finais}

O objetivo deste estudo foi discutir as ações das participantes de um encontro do curso de contação de histórias em PLA, na China, através da análise de instruções-em-ação, incrementadas pelo trabalho de categorização. Além disso, relaciona-se as interações em sala de aula com a pedagogia de projetos, metodologia de ensino e aprendizagem adotada para o curso.

Julgamos importante destacar a incorporação das categorias de pertencimento nas ações dos participantes que, ao se colocarem na condição de um grupo de contação de histórias, agem como tal, em um ato de confluência para que as metas da atividade sejam cumpridas, investindo,

${ }^{21}$ Recipient design, nas palavras de Sacks (1995). 
por exemplo, na ação de dar uma sugestão (linhas 52-53 do Segmento 3) à contadora que tem o foco de atenção no momento da interação.

Apesar de no início do excerto ser possível perceber que a ação de Luna invoca a categoria de professora, a responsabilidade de fazer comentários e dar sugestões não fica somente a seu cargo e nem é repassada para ela pelas participantes - ou pela não realização das ações por parte de outras participantes. Assim, temos uma sala de aula centrada na interação, onde as ações são menos dependentes de uma sistemática de tomada de turnos pré-alocada. Tal característica assemelha-se mais a conversa cotidiana, em um contexto em que a linguagem não é apenas um objeto de ensino, mas também uma forma de se realizar ações no mundo.

Essa característica menos ritualizada da aula aqui observada pode ser explicada pelo fato de os participantes, em interações anteriores ao trecho analisado, revisarem as atribuições do que significa ser um membro do curso e fazer parte do grupo. Kniphoff (2012), ao analisar interações em uma sala de aula em que a tarefa de realizar a avaliação de um trabalho fica a cargo de um grupo de alunos, discute como a não negociação e não formulação explícita das atribuições de cada categoria envolvida (como jurado) tornou mais difícil para os participantes levarem a cabo a proposta da tarefa no momento da interação. Desta forma, mostra-se relevante nesses cenários a explicitação do que é esperado dos participantes e formulações claras de instruções que auxiliem na realização das atividades. Todavia, esses procedimentos não fornecem garantia alguma sobre como as ações locais e o contexto serão produzidos, exibidos e interpretados pelos participantes nas interações. É preciso olhar para a atualização, ou seja, a concretização das instruções (GARFINKEL, 2002) na conduta situada dos membros sociais.

Parece-nos, ainda, fundamental destacar a realização e a conclusão com sucesso das ações pretendidas pelas participantes. Ao refletir sobre este cenário, através de uma perspectiva etnometodológica, o foco é no que as participantes conseguem fazer (e não no que elas não conseguem fazer). Acreditamos que, a partir desse excerto, possamos entender de forma mais concreta a noção de membro na perspectiva da EM, tendo em vista que esse termo é definido no domínio da língua em uso. Garfinkel e Sacks (1970) definem que o termo "membro" indica o domínio da linguagem natural, a capacidade de, a partir do uso do conhecimento comum dos fatos naturais, reconhecer e produzir ações adequadas ao contexto local e imediato de cada encontro social (GARFINKEL, 1967, p. 275; HERITAGE, 1984, p. 139). 
Assim, o que define a condição de pertencimento não tem relação somente com o domínio de uma língua específica em si, ou com ser membro de uma comunidade linguística, mas com a capacidade de ser socialmente competente, compartilhando expectativas e métodos interativos (etnométodos) num plano de conhecimento de senso comum com os outros membros.

\section{Agências de fomento à pesquisa}

Este trabalho recebeu o apoio financeiro das seguintes agências de fomento à pesquisa:

- Fundo para o Desenvolvimento das Ciências e da Tecnologia de Macau (FDCT), projeto $n^{\circ} .0054 / 2019 / \mathrm{A} 1$

- Gabinete de Apoio à Investigação e de Transferência do Conhecimento, projeto nº. MYRG2016-0003-FAH.

\section{Contribuição dos Autores}

Bruna Morelo é Doutoranda em Linguística Aplicada pela Universidade de Macau e Mestra em Linguística Aplicada pela Universidade Federal do Rio Grande do Sul. Na área de Português como Língua Adicional, destaca-se o trabalho com ensino de português através da contação de histórias da tradição oral. Realiza pesquisas sobre letramentos, ensino e aprendizagem de gêneros discursivos orais e fala-em-interação em sala de aula (EM, ACE, MCA). Ricardo Moutinho é professor associado de linguística e membro do Instituto de Estudos Avançados em Humanidades e Ciências Sociais da Universidade de Macau. Realiza estudos nas áreas da Etnometodologia, Análise da Conversa e Análise de Categorização de Pertencimento. Atualmente foca os seguintes tópicos: momentos de aprendizagem; ações instruídas; jogos online.

\section{Referências}

ALMEIDA, A. N. A construção de masculinidades na fala-em-interação em cenários escolares. 2009. 298f. Tese (Doutorado em Linguística Aplicada) - Instituto de Letras, Universidade Federal do Rio Grande do Sul, Porto Alegre, 2009.

BARBOSA, M. C. S. Por que voltamos a falar e a trabalhar com Pedagogias de Projetos? Projeto: Revista de Educação, [S.l.] v. 3, n. 4, 8-13, 2004. 
BAKHTIN, M. Estética da criação verbal. Tradução de Paulo Bezerra. São Paulo: Martins Fontes, 2003.

BULLA, G. da S. A realização de atividades pedagógicas colaborativas em sala de aula de português como língua estrangeira. 2007. 126f. Dissertação (Mestrado em Linguística Aplicada) - Instituto de Letras, Universidade Federal do Rio Grande do Sul, Porto Alegre, 2007.

CHEN, Y. Organização do reparo e a intersubjetividade em sala de aula: um estudo de caso em um curso de contação de histórias em PLE em Macau. 2018. 73f. Dissertação (Mestrado em Linguística Aplicada) - Faculdade de Letras. Universidade de Macau, Taipa, 2018.

CLARK, H. O uso da linguagem. Cadernos de Tradução, Porto Alegre, n. 9, p. 49-71, 2000.

DILLI, C.; MORELO, B. A contação de histórias no ensino de gêneros orais em português como língua adicional. Orientes do Português, Taipa, Macau, v. 1, n .1, p. 91-102, 2019.

EGLIN, P. What Do We Do Wednesday? On Beginning the Class as UniversitySpecific Work: A Preliminary Study. Canadian Review of Sociology, Mississauga, v. 46, n. 1, p. 39-57, 2009. DOI: https://doi.org/10.1111/j.1755-618X.2009.01202.x

GARCEZ, P. M. A perspectiva da análise da conversa etnometodológica sobre o uso da linguagem em interação social. In: LODER, L. L.; JUNG, N. M. (org.). Falaem-interação social: introdução à análise da conversa etnometodológica. Campinas: Mercado de Letras, 2008. p. 8-17.

GARCEZ, P. M. A Organização da fala-em-interação na sala de aula: controle social, reprodução de conhecimento, construção conjunta de conhecimento. Calidoscópio, São Leopoldo, v. 4, n. 1, p. 66-80, 2006.

GARFINKEL, H. Ethnomethodology's Program: Working out Durkheim's Aphorism. Lanham: Rowman \& Littlefield Publishers, 2002.

GARFINKEL, H. Studies in Ethnomethodology. Cambridge: Polity Press, 1967.

GARFINKEL, H.; SACKS, H. On Formal Structures of Practical Actions. In: MCKINNEY, J. C.; TIRYAKIAN, E. A. (ed.). Theoretical Sociology: Perspectives and Developments. New York: Appleton-Century-Crofts, 1970. p. 338-366.

GREENO, J. G. Learning in Activity. In: R. K. SAWYER (ed.). The Cambridge Handbook of the Learning Sciences. New York: Cambridge University Press, 2006. p. 79-96. DOI: https://doi.org/10.1017/CBO9780511816833.007 
GREIFFENHAGEN, C.; WATSON, R. Visual Repairables: Analysing the Work of Repair in Human-Machine Interaction. Visual Communication, Thousand Oaks, v. 8, n. 1, p. 65-90, 2009. DOI: https://doi.org/10.1177/1470357208099148

GURWITSCH, A. The Field of Consciousness. Pittsburgh: Duquesne University Press, 1964.

HERITAGE, J. Garfinkel and Ethnomethodology. Cambridge: Polity, 1984.

HESTER, S.; EGLIN, P. (ed.). Culture in Action: Studies in Membership Categorization Analysis. Washington, D.C.: University Press of America. 1997.

HUSTLER, D. E.; PAYNE, G. C. F. Power in the Classroom. Research in Education, Thousand Oaks, v. 28, n.1, p. 49-64, 1982. DOI: https://doi. org/10.1177/003452378202800105

KANITZ, A.; FRANK, I. Aprendizagem enquanto produção conjunta de conhecimento: avançando tarefas e alcançando entendimentos satisfatórios na fala-em-interação. Revista Brasileira de Linguística Aplicada, Belo Horizonte, v. 14, n. 1, p. 111-140, 2014. DOI: https://doi.org/10.1590/S1984-63982014005000001

KNIPHOFF, A. M. O gerenciamento de categorias de pertencimento institucionais no trabalho de avaliação pedagógica coletiva na fala-em-interação de sala de aula. 2012. $142 \mathrm{f}$. Dissertação (Mestrado em Linguística Aplicada) - Instituto de Letras, Universidade Federal do Rio Grande do Sul, Porto Alegre, 2012.

LIBERMAN, K. More Studies in Ethnomethodology. Albany: State University of New York Press, 2013.

LUKE, K. K. Storytelling in Multiple contexts. Chinese Language and Discourse, Amsterdam, v. 7, n. 2, p. 297-340, 2016. DOI: https://doi.org/10.1075/ cld.7.2.05luk

MACBETH, D. H. Teacher Authority as Practical Action. Linguistics and Education, Amsterdam, v. 3, p. 281-313, 1991. DOI: https://doi.org/10.1016/08985898(91)90012-8

MACBETH, D. Classrooms as Installations: Direct Instruction in the Early Ages. In: HESER, S.; FRANCIS D. (ed.). Local Educational Order. Amsterdã: John Benjamins Publishing Company, 2000. p. 21-72. DOI: https://doi.org/10.1075/ pbns.73.03mac

MARKHAM, T. Project Based Learning. Teacher Librarian, Bowie, v. 39, n. 2, p. 38-42, 2011. DOI: https://doi.org/10.12968/prtu.2011.1.1.38

MAJLESI, A. R.; BROTH, M. Emergent Learnables in Second Language Classroom Interaction. Leaning, Culture and Social Interaction, Amsterdam, v. 1, n. 3-4, p. 193-207, 2012. DOI: https://doi.org/10.1016/j.lcsi.2012.08.004 
MEHAN, H. Learning Lessons. Cambridge, MA: Harvard University Press, 1979.

MOUTINHO, R. Context Formulation and the Invocation of Membership Categories in an L2 Classroom Setting. Journal of Pragmatics, [S.1.], v. 140, n. 1, p. 100-111, 2019. DOI: https://doi.org/10.1016/j.pragma.2018.12.002

PAYNE, G. C. F.; CUFF, E. C. Introduction: Some Theoretical Considerations for Practical Research. In: . (ed.). Doing Teaching. Londres: Batsford Academic and Educational, 1982. p. 1-9.

SACKS, H. Lectures on Conversation, Oxford: Blackwell, 1995. v. I, II. DOI: https:// doi.org/10.1002/9781444328301

SACKS, H. On Formulating Context. Pragmatics Microfiche, Oxford, v. 1, n. 7, p. F5-G8. 1976.

SACKS, H. On the Analyzability of Stories by Children. In: GUMPERZ, J. J.; HYMES, D. (org.). Directions in Sociolinguistics: The Ethnography of Communication. New York: Holt, Rinehart and Winston, 1972. p. 325-345.

SACKS, H.; SCHEGLOFF, E. A.; JEFFERSON, G. A Simplest Systematics for the Organization of Turn-Taking for Conversation. Language, Washington D.C., v. 50, n. 4, p. 695-737, 1974. DOI: https://doi.org/10.2307/412243

SALIMEN, P. G. A atividade pedagógica de encenar em grupos na sala de aula de língua estrangeira: pedidos de ajuda, ofertas de ajuda e aprendizagem. 2009. 159f. Dissertação (Mestrado em Linguística Aplicada) - Instituto de Letras, Universidade Federal do Rio Grande do Sul, Porto Alegre, 2009.

SCHEGLOFF, E. A. When “Others” Initiate Repair. Applied Linguistics, Oxford, v. 21, n. 2, p. 205-243, 2000. DOI: https://doi.org/10.1093/applin/21.2.205

SCHEGLOFF, E. A. Repair After Next Turn: The Last Structurally Provided Defense of Intersubjectivity in Conversation. American Journal of Sociology, Chicago, v. 97, n. 5, p. 1295-1345, 1992. DOI: https://doi.org/10.1086/229903

SCHEGLOFF, E. A. Conversation Analysis and Socially Shared Cognition. In: RESNICK, L.; LEVINE, J.; BEHREND, S. (org.). Perspectives on Socially Shared Cognition. Washington, D.C.: American Psychological Association, 1991. p. 150-171. DOI: https://doi.org/10.1037/10096-007

SCHEGLOFF, E. A. Between Micro and Macro: Contexts and Other Connections. In: ALEXANDER, J. K. C.; GIESEN, B.; MÜNCH, R.; SMELSER, N. J. (org.). The Micro-Macro Link. Berkeley: University of California Press, 1987. p. 207-234. 
SCHEGLOFF, E. A.; JEFFERSON, G.; SACKS, H. The Preference for SelfCorrection in the Organization of Repair in Conversation. Language, Washington D.C., v. 53, n.2, p. 361-382, 1977. DOI: https://doi.org/10.1353/lan.1977.0041

SCHLATTER, M.; GARCEZ, P. M. Linguas adicionais na escola: aprendizagens colaborativas em inglês. Erechim: Edelbra. 2012.

SCHNEUWLY, B. Palavra e ficcionalização: um caminho para o ensino da linguagem oral. In: SCHNEUWLY, B.; DOLZ, J. Gêneros orais e escritos na escola. São Paulo: Mercado de Letras, 2004. p. 129-147.

SEEDHOUSE, P. The Interactional Architecture of the Language Classroom: A Conversation Analysis Perspective. Malden: Blackwell, 2004.

SEEDHOUSE, P. L2 Classroom Interaction as a Complex Adaptive System. In: MARKEE, N. (ed.). The Handbook of Classroom Discourse and Interaction. Hoboken: Wiley-Blackwell, 2015. DOI: https://doi.org/10.1002/9781118531242.ch22

SPEIER, M. The Everyday World of the Child. In: DOUGLAS, J. D. (ed.). Understanding Everyday Life: Towards a Reconstruction Of Sociological Knowledge. Chicago: Aldine Publishing. 1970. p. 188-217. DOI: https://doi. org/10.4324/9781351327329-8

SPEIER, M. Some Conversational Problems for Interactional Analysis. In: SUDNOW, D. (ed.) Studies in Social Interaction. New York: Free Press, 1972. p. 397427.

TABENSKY, A. Non-Verbal Resources and Storytelling in Second Language Classroom Interaction. Journal of Applied Linguistics, Sheffield, v. 5, n. 3, p. 321-348, 2012. DOI: https://doi.org/10.1558/japl.v5i3.321

WATSON, D. R. Some General Reflections on 'Categorization' and 'Sequence' in the Analysis of Conversation. In: HESTER, S.; EGLIN, P. (ed.). Culture in Action: Studies in Membership Categorization Analysis. Washington, D.C.: University Press of America, 1997. p. 49-75.

WATSON, R.; GASTALDO, E. Etnometodologia e análise da conversa. Petrópolis: Vozes. 2015.

WATSON, G.; IRWIN, A. The Mundane Miracle of Social Order. Ethos: Journal of Anthropology, Hoboken, v. 61, n. 1-2, p. 85-102, 1996. DOI: https://doi.org/10.10 80/00141844.1996.9981529

WIEDER, D. L. Language and Social Reality: The Case of Telling the Convict Code. Paris: Mouton. 1974. DOI: https://doi.org/10.1515/9783111410999 


\section{Apêndice 1: Convenções de Transcrição:}

\begin{tabular}{|l|l|l|}
\hline$\cdot$ & (ponto final) & entonação descendente \\
\hline$?$ & (ponto de interrogação) & entonação ascendente \\
\hline, & (vírgula) & entonação de continuidade \\
\hline$::$ & (dois pontos) & prolongamento do som \\
\hline PALAVRA & (maiúsculas) & fala em volume alto \\
\hline${ }^{\circ}$ palavra ${ }^{\circ}$ & (sinais de graus) & fala em voz baixa \\
\hline$>$ palavra $<$ & (sinais de maior e menor) & fala acelerada \\
\hline$<$ palavra $>$ & (sinais de menor e maior) & fala desacelerada \\
\hline Hh & (série de h's) & aspiração ou riso \\
\hline[] & (colchetes) & fala simultânea ou sobreposta \\
\hline$=$ & (sinais de igual) & elocuções contíguas \\
\hline$(5.0)$ & (números entre parênteses) & $\begin{array}{l}\text { medida de silêncio (em segundos e } \\
\text { décimos de segundos) }\end{array}$ \\
\hline$(($ olhando para o teto)) & (parênteses duplos) & descrição de atividade não-verbal \\
\hline
\end{tabular}




\section{Apêndice 2:}

Excerto: "é engraçado para as crianças brasileiras"

( $8^{\circ}$ encontro, interior da China - 02/06/2017)

(Vídeo 1 - 1:30:40 / 01:23:15 - 1:25:10)

01 Luna: que história bonita (1,9) alguém tem alguma

02

pergun ta ( (olha um lado e para o outro))

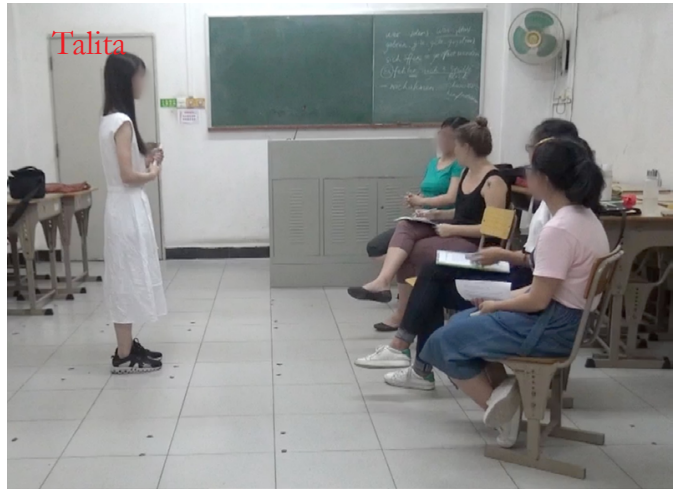

Figura 1

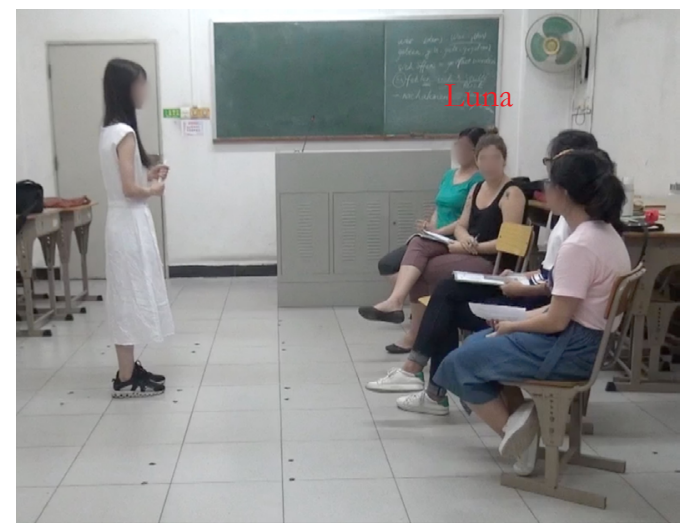

Fugura 2

$03 \quad(1,8)$

04 Nubia: ã:: (.) ã:: (.) no início (.) cê: ã: disse eles 05

ã: : tem $\circ::$ ã compromisso= 


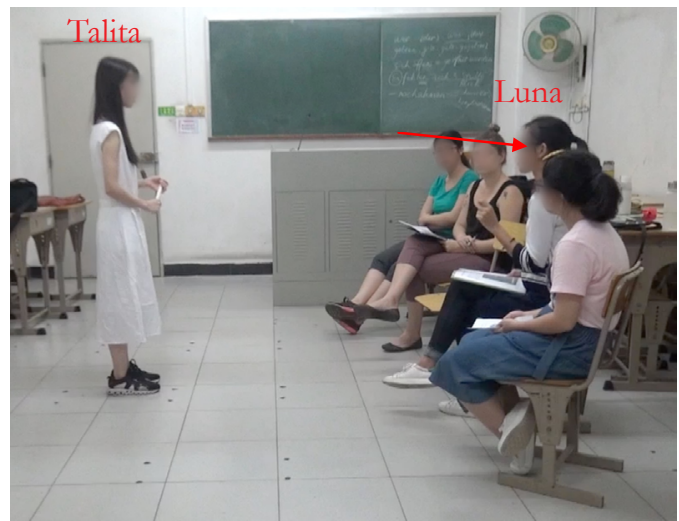

Figura 3

08 Nubia:
Talita:

. 
18 Luna: hu: : :m

19 (.)

20 Nubia: ã:: na china antiga quando ã::m (.) ã: os amigos

21 ã: os ami- ã: o: : as (.) as ( (coloca a mão no

22 queixo e olha para cima)) as=

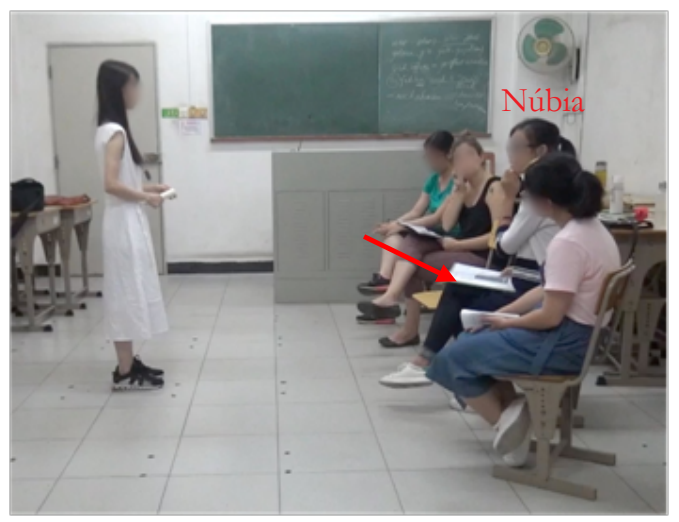

Figura 5
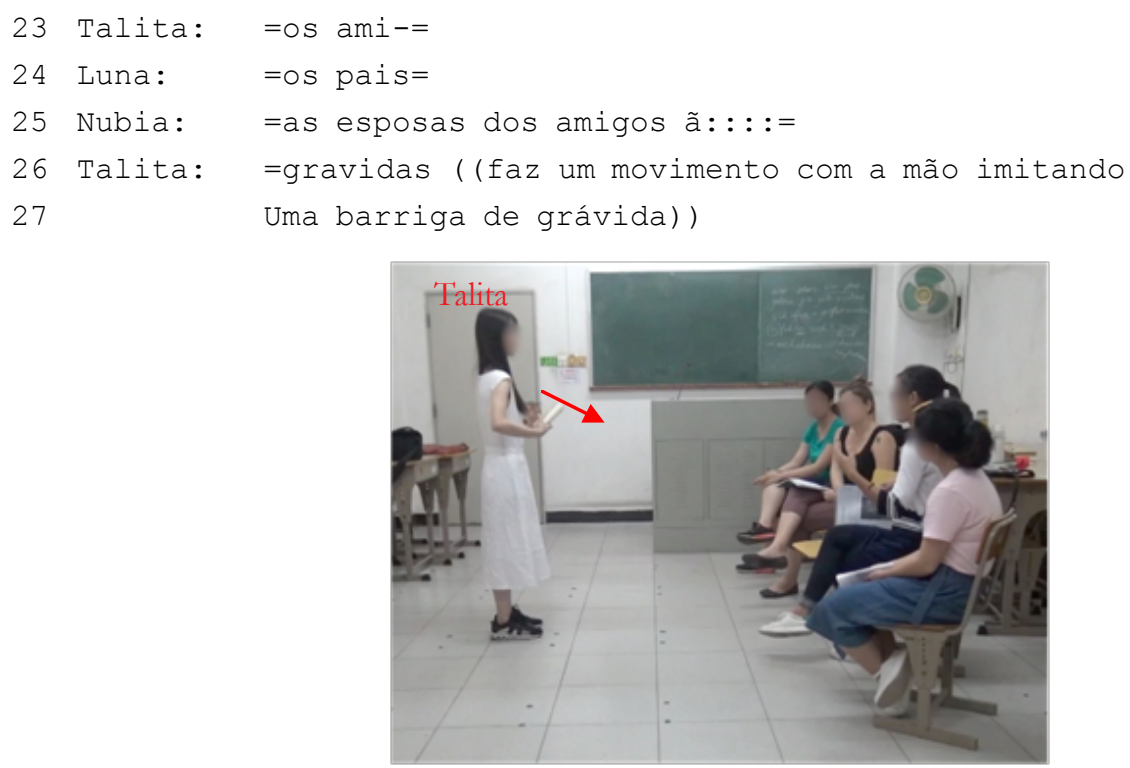

Figura 6 


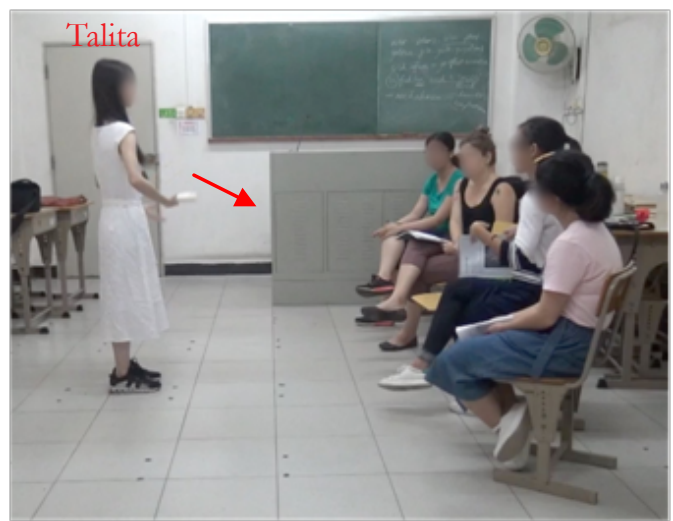

Figura 7

28 Nubia:

=a: gra: são gra- grávidos no mesmo tempo eles

ã:m $(1,0)$ ã:m ((faz movimento com uma das mãos))

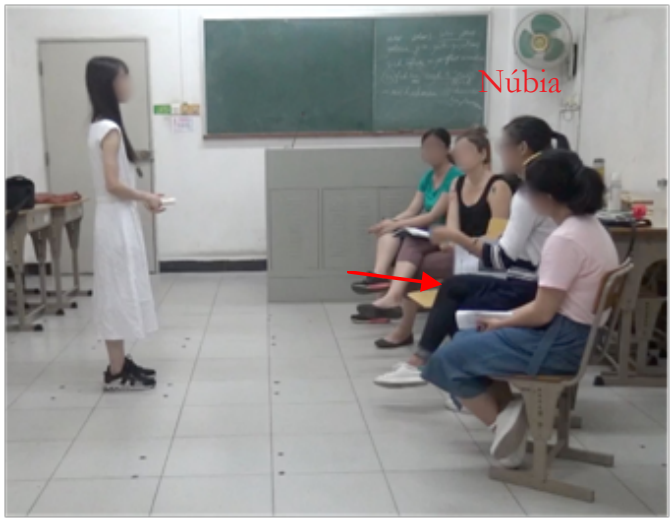

Figura 8

30

32 Talita:

33

34 Luna: $(\cdot)$

combinar eles vão]combinar o: : [casamento [eles vão combinar, ] [as vezes para as duas crianças para [ser a: ( )

[a: : : : sim sim a: entendi 


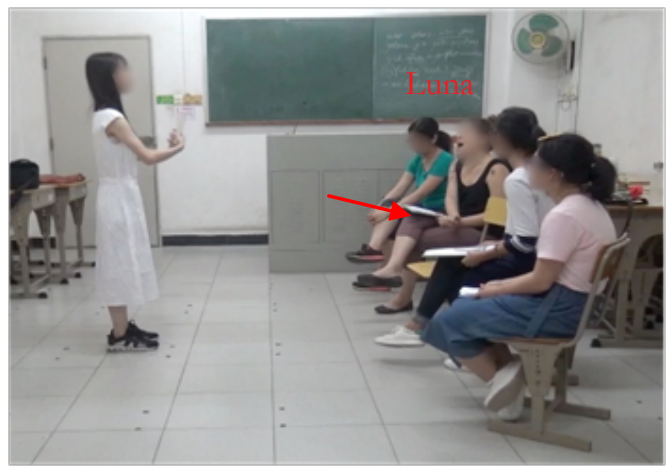

Figura 9

39 Nubia: $=[\operatorname{sim}$

40 Talita: $=[$ sim

41 Adriana: $=[\operatorname{sim}$

42 Luna: =ah e isso era muito normal, =

43 Nubia: $=[\operatorname{sim}$

44 Talita: $=[\mathrm{sim}$

45 Adriana: $=[\mathrm{sim}$

46

47 Luna:

48 Talita:

49

50

51

52 Nubia:

53

54 Adriana:

56 Luna:

\section{(.)}

$\mathrm{a}::: \uparrow$

isso está na literatura na na literatura

clássica: chinesa (.) isso é muito normal= =hum (.) a: interessante

(.)

acho que pode contar mais (.) porque é muito interessante $\mathrm{hhh}=$ =e é é é engraçada para (.) é o costume é engraçado para (.) as crianças brasileiras é:: é um costume diferente né,

Data de submissão: 03/03/2020. Data de aprovação: 21/12/2020. 